University of Nebraska - Lincoln

DigitalCommons@University of Nebraska - Lincoln

Publications, Agencies and Staff of the U.S.

Department of Commerce

U.S. Department of Commerce

2011

Bayesian state-space model of fin whale abundance trends from a 1991-2008 time series of line-transect surveys in the California Current

Jeffrey E. Moore

NOAA, jeff.E.Moore@noaa.gov

Jay Barlow

NOAA, jay.barlow@noaa.gov

Follow this and additional works at: https://digitalcommons.unl.edu/usdeptcommercepub

Part of the Environmental Sciences Commons

Moore, Jeffrey E. and Barlow, Jay, "Bayesian state-space model of fin whale abundance trends from a 1991-2008 time series of line-transect surveys in the California Current" (2011). Publications, Agencies and Staff of the U.S. Department of Commerce. 294.

https://digitalcommons.unl.edu/usdeptcommercepub/294

This Article is brought to you for free and open access by the U.S. Department of Commerce at DigitalCommons@University of Nebraska - Lincoln. It has been accepted for inclusion in Publications, Agencies and Staff of the U.S. Department of Commerce by an authorized administrator of DigitalCommons@University of Nebraska - Lincoln. 


\title{
Bayesian state-space model of fin whale abundance trends from a 1991-2008 time series of line-transect surveys in the California Current
}

\author{
Jeffrey E. Moore* and Jay Barlow \\ NOAA, National Marine Fisheries Service, Southwest Fisheries Science Center, Protected Resources Division, 3333 \\ North Torrey Pines Ct., La Jolla, CA 92037, USA
}

\begin{abstract}
Summary
1. Estimating temporal trends in animal abundance is central to ecology and conservation, but obtaining useful trend estimates is challenging when animal detection rates vary across surveys (e.g. because of differences in observers or conditions). Methods exist for obtaining abundance estimates using capture-recapture and distance sampling protocols, but only recently have some of these been extended to allow direct estimation of abundance trends when detection rates vary. Extensions to distance sampling for $>2$ surveys have not yet been demonstrated.

2. We demonstrate a Bayesian approach for estimating abundance and population trends, using a time series of line-transect data for endangered fin whales Balaenoptera physalus off the west coast of the United States. We use a hierarchical model to partition state and observation processes. Population density is modelled as a function of covariates and random process terms, while observed counts are modelled as an overdispersed Poisson process with rates estimated as a function of population density and detection probability, which is modelled using distance sampling theory. We used Deviance Information Criteria to make multi-model inference about abundance and trend estimates.

3. Bayesian posterior distributions for trend parameters provide strong evidence of increasing fin whale abundance in the California Current study area from 1991 to 2008, while individual abundance estimates during survey years were considerably more precise than previously reported estimates using the same data. Assuming no change in underlying population dynamics, we predict continued increases in fin whale numbers over the next decade. Our abundance projections account for both sampling error in parameter estimates and process variance in annual abundance about the mean trend.

4. Synthesis and applications. Bayesian hierarchical modelling offers numerous benefits for analysing animal abundance trends. In our case, these included its implicit handling of sampling covariance, flexibility to accommodate random effects and covariates, ability to compare trend models of different functional forms and ability to partition sampling and process error to make predictions. Ultimately, by placing distance sampling within a more general hierarchical framework, we obtained more precise abundance estimates and an inference about fin whale trends that would have otherwise been difficult.
\end{abstract}

Key-words: Balaenoptera physalus, cetacean density, distance sampling, hierarchical modelling, multi-model inference

\section{Introduction}

Understanding temporal trends in wildlife population abundance is a cornerstone of ecological research, population risk assessment and natural resource management (Krebs 2001;
Morris \& Doak 2002; Williams, Nichols \& Conroy 2002; Rodrigues et al. 2006). Obtaining useful estimates of abundance, let alone abundance trends, from field surveys is not straightforward for many populations because of imperfect and heterogeneous detection of individuals within and, more importantly, among surveys (Kéry \& Schmidt 2008; Kéry et al. 2009; Kéry \& Royle 2010). An entire research field has 
guided survey design and statistical methodology to improve abundance estimation when only a fraction of the population is counted during surveys. Most methods can be classified broadly into capture-recapture (Borchers, Buckland \& Zucchini 2002; Amstrup, McDonald \& Manly 2005) and distance sampling protocols (Buckland et al. 2001, 2004). In this study, we focus on the latter, which uses frequency distributions of detection distances to obtain unbiased animal density and abundance estimates. Thomas, Burnham \& Buckland (2004) provide the only guidance we know of for estimating abundance trends from $>2$ distancebased abundance estimates with proper accounting of sampling covariance, but their approach is somewhat post hoc in that trends are fit to time series of abundance estimates obtained individually via distance methodology, rather than estimating both trends and abundance estimates directly within a single framework.

Here, we describe a hierarchical Bayesian approach that allows for estimation of and statistical inference on trend parameters, time- and strata-specific density and abundance, covariate effects on detectability and process and sampling error components within a single framework. Effectively, we combine a generalized linear model for animal density with a line-transect model of detectability. Hierarchical statespace models allow data to be formally represented as the outcome of distinct stochastic processes: a state process that describes the underlying ecological dynamics of interest and an observation process that describes the relationship between the unobserved ecological state variable and the observed data (de Valpine \& Hastings 2002; Clark 2007; Royle \& Dorazio 2008). In the current context, the state model represents change in true population density or abundance through time $\left(N_{t}\right)$, while the observation model characterizes the probability of observing $n_{t}$ individuals during surveys (the data) given $N_{t}$ and the detection probability process specific to the distance sampling (line-transect) survey design.

There are conceptual and computational advantages of formulating ecological problems hierarchically (Royle \& Dorazio 2008; Cressie et al. 2009). Conceptually, isolating the biological (state) process from the 'nuisance' (observation) process provides an explicit, mechanistic and ultimately more interpretable description of how the data were generated. An important practical benefit is that the biological model may be used to make predictions about future values of the state variable without requiring information about future values of the observation process; we will provide an example of this utility in our case study. Computationally, hierarchical models are ideal for partitioning sources of variance (e.g. process vs. sampling error) and handling random effect variables, and they are well suited to analysis by Bayesian methods (Cressie et al. 2009; Congdon 2010; Link \& Barker 2010). Bayesian methods enable probabilistic inference about parameters and trends based on summaries of posterior probability distributions (vs. null hypothesis testing), they permit the use of multiple data types collected at different scales and use of prior informa- tion, and they enable model selection and multi-model inference in a straightforward manner. We demonstrate application of a hierarchical Bayesian trend model by assessing fin whale Balaenoptera physalus L. abundance trends in the California Current from 1991 to 2008 from multiple years of line-transect survey data. We proceed to use the fitted trend model to make predictions of fin whale abundance 8 years into the future, which has relevance for estimating incidental take limits under the US Marine Mammal Protection Act in the absences of concurrent abundance estimates (NMFS 2005).

\section{Cetacean abundance surveys in the California Current}

Cetacean abundance surveys in the California Current ecosystem, based on distance sampling design, have been conducted every few years by the NOAA Southwest Fisheries Science Center (SWFSC) since 1991. Year-specific abundance estimates for many cetacean species along the US west coast have been recently published based on these surveys (Barlow \& Forney 2007; Barlow 2010). Ideally, these abundance estimates should be useful for determining whether cetacean populations have increased, decreased or remained constant over the 17-year survey period. Beyond the obvious value of such information for studying marine ecosystem dynamics and impacts of humans thereon, trend estimates are necessary for guiding decision-making under several legal policies affecting marine mammals (US Marine Mammal Protection Act, Endangered Species Act and International Convention for the Regulation of Whaling). Inferences about cetacean abundance trends are elusive, however, because of high levels of sampling error in individual abundance estimates [e.g. large coefficients of variation (CVs)] that make trends difficult to detect given the limited abundance data available and a statistical paradigm of null hypothesis testing (Taylor et al. 2007). Moreover, sampling covariance in abundance estimates because of pooling of data across years to estimate species-detection functions can invalidate statistical inference from conventional trend analyses by underestimating standard errors of model parameters.

For purposes of illustration, we limit application of our Bayesian trend analysis to distance sampling data for fin whales, which are listed as Endangered under the US Endangered Species Act. We chose this species for initial study because of its conservation status, because fin whale counts are higher than for most other cetaceans in the California Current (i.e. relatively large sample size), and because their relatively high detectability and small group sizes allow for simple covariate models of detection and relatively precise estimates of abundance compared to most other species. Additionally, fin whale abundance point estimates since 1991 give the strongest impression out of all species of a probable trend (increasing) (Barlow \& Forney 2007). Therefore, we considered this species a good test case because if trends are not statistically detectable for this species, they are unlikely to be detected for other species in this system. 


\section{Materials and methods}

\section{SURVEY METHODS AND DATA}

We provide here a brief overview of survey methodology. For details, see Kinzey, Olson \& Gerrodette (2000) and Barlow \& Forney (2007). Shipboard line-transect surveys were conducted in summer and autumn of 1991, 1993, 1996, 2001, 2005 and 2008. The study area has been consistently divided into four strata, from north to south (Fig. 1): Oregon-Washington (OW), Northern California (NC), Central California (CC) and Southern California (SC). All strata were surveyed in all years, except that Oregon-Washington was not surveyed in 1991 or 1993. Transects followed a uniform grid pattern anchored to a different random starting point each survey year. Vessels travelled at 9-10 knots along transects. Observers used $25 \times$ binoculars to sight cetacean groups. Detection distances and angles to sighted cetacean groups were converted into perpendicular distances to the transect lines. Whale group sizes were estimated as the average of observers' individual estimates (typically three estimates per group). In previously published analyses that included data from all surveyed species, group size estimates were adjusted for unique observer effects (Gerrodette \& Forcada 2005; Barlow \& Forney 2007; Barlow 2010). However, those calibrations were designed to improve group size estimation of dolphins; they may not be appropriate for large whales. Therefore, no group size adjustments were performed in the current fin whale analysis.

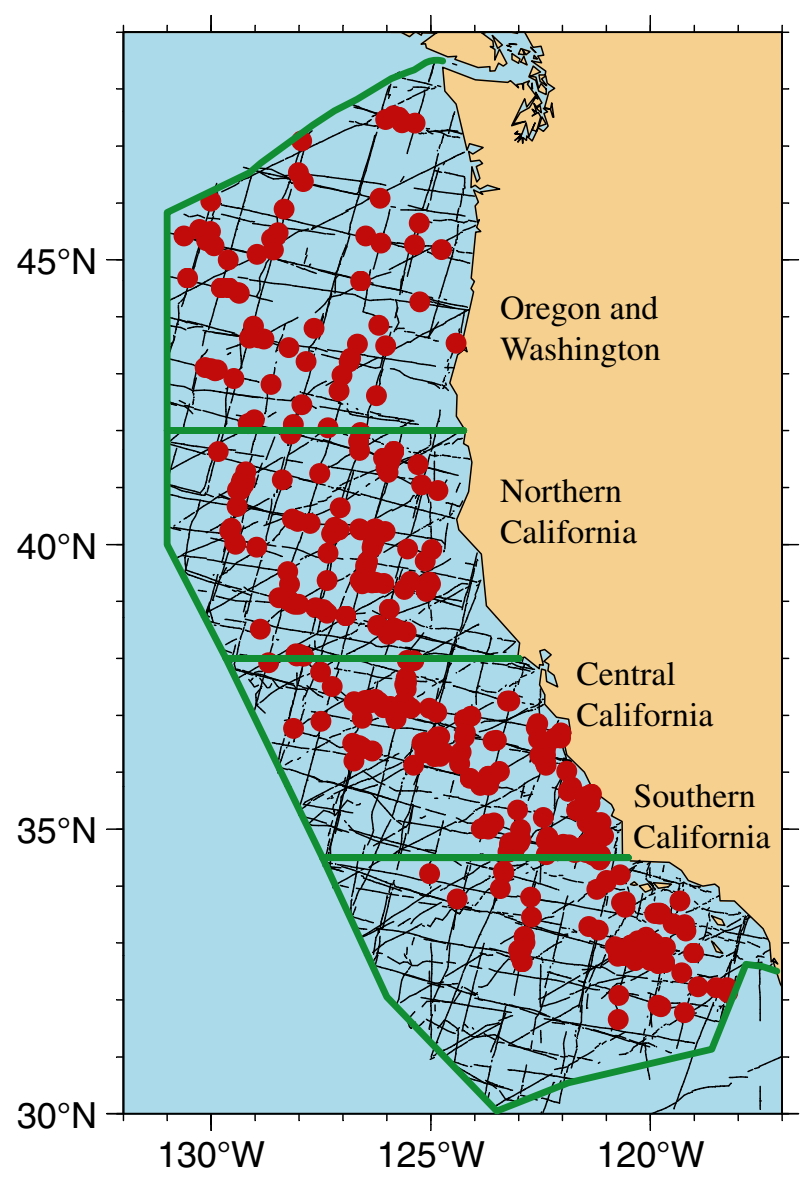

Fig. 1. Study area, geographic strata, fin whale sighting locations and transects surveyed.
Only detections and effort occurring during sea state conditions of Beaufort 5 or better were included in the analysis. For estimating the parameters that describe the decline in detectability with distance from the transect line, we used pooled data from three species: fin whales, blue whales Balaenoptera musculus and killer whales Orcinus orca. The latter two species have very similar detection characteristics to fin whales (Barlow, Gerrodette \& Forcada 2001), so their inclusion increased sample size (Barlow \& Forney 2007). Distance data were truncated to only include observations $<4 \mathrm{~km}$ from the transect line; this truncation distance is consistent with previous analyses (e.g. Barlow \& Forney 2007) and eliminated close to $15 \%$ of observations, consistent with recommendations by Buckland et al. (2001). Total survey effort (on-effort transect length), counts of fin whale groups and recorded groups sizes by year and stratum are summarized in Table 1.

Many covariates associated with each detected cetacean group are recorded during surveys. Based on previous covariate model selection for fin whale detectability (Barlow \& Forney 2007), we only considered a few detectability covariates in this analysis: ship (surveys occurred on the David Starr Jordan, McArthur, and McArthur II), strata, rainFog (binary variable, coded as 1 if rainy or foggy) and year. All variables were modelled as fixed effects except for year, which was modelled as a random effect (see below); this variable was not evaluated in previous analyses.

\section{ANALYTICAL METHODS}

Following Buckland et al. (2001), $\hat{N}_{j t}=\hat{D}_{j t} A_{j t}$, where $N_{j t}$ is population abundance, $D_{j t}$ is population density, and $A_{j t}$ is the study area of stratum $j$ during year $t$. Density may be estimated:

$\hat{D}_{j t}=\frac{n_{j t} \cdot \hat{s}_{j t} \cdot \hat{f}_{j t}(0)}{2 \cdot L_{j t} \cdot \hat{c}}$

eqn 1

where $n_{j t}$ is number of groups detected; $s_{j t}$ is mean group size; $f_{j t}(0)$ is the evaluation at distance $y=0$ of the probability density function (pdf) for detection probability; $c$ is the detection probability on the transect line if not assumed to be 1 ; and $L_{j t}$ is the on-effort transect length. We assume $c$ does not vary with $j$ or $t$.

\section{Process model}

To formulate the problem hierarchically, we partition the model into process and observation components. The process model describes how population density changes through time. The most general model we considered describes variation in density as a function of mean stratum differences (fixed intercepts), stratum-specific trend coefficients (random slopes) and a stochastic component (random variable) for each stratum-year $(j, t)$. If the population is changing exponentially, the full density model is:

$$
\begin{aligned}
& D_{j t}=\exp \left(\beta_{d 0}+\beta_{d k}\left(\operatorname{strata}_{k}\right)+\beta_{d 4, j} t+\gamma_{j t}\right), \\
& \beta_{d 4, j} \sim \operatorname{Norm}\left(\beta_{D 4}, \sigma_{D 4}\right), \\
& \gamma_{j t} \sim \operatorname{Normal}\left(0, \sigma_{d}\right),
\end{aligned}
$$

where subscripts $d$ and $D$ denote density parameters and hyperparameters; $\beta_{d 0}$ is an intercept for density; $\beta_{d k}$ for $k=1,2,3$, are fixed effects for binary dummy variables for strata $\mathrm{SC}, \mathrm{CC}$ and $\mathrm{NC}$, 


\begin{tabular}{|c|c|c|c|c|c|c|}
\hline \multirow[b]{2}{*}{ Stratum } & \multicolumn{6}{|l|}{ Year } \\
\hline & 1991 & 1993 & 1996 & 2001 & 2005 & 2008 \\
\hline \multicolumn{7}{|c|}{ Oregon and Washington } \\
\hline$n_{j t}$ & No data & No data & 8 & 10 & 11 & 17 \\
\hline$L_{j t}$ & & & 4337 & 3098 & 2951 & 3237 \\
\hline$s_{j t}$ & & & $1 \cdot 4$ & $1 \cdot 2$ & $1 \cdot 4$ & $2 \cdot 5$ \\
\hline \multicolumn{7}{|c|}{ Northern California } \\
\hline$n_{j t}$ & 2 & 6 & 4 & 13 & 29 & 13 \\
\hline$L_{j t}$ & 3018 & 2085 & 3287 & 2376 & 2665 & 2396 \\
\hline$s_{j t}$ & $1 \cdot 5$ & 1.9 & $1 \cdot 8$ & 1.9 & $2 \cdot 1$ & $2 \cdot 3$ \\
\hline \multicolumn{7}{|c|}{ Central California } \\
\hline$n_{j t}$ & 16 & 19 & 35 & 5 & 25 & 17 \\
\hline$L_{j t}$ & 2967 & 1523 & 3056 & 1608 & 2385 & 2894 \\
\hline$s_{j t}$ & 1.9 & $2 \cdot 1$ & $2 \cdot 2$ & $3 \cdot 3$ & $2 \cdot 3$ & $2 \cdot 4$ \\
\hline \multicolumn{7}{|c|}{ Southern California } \\
\hline$n_{j t}$ & 5 & 4 & 16 & 1 & 9 & 15 \\
\hline$L_{j t}$ & 4040 & 2627 & 3994 & 2455 & 2837 & 3037 \\
\hline$s_{j t}$ & $1 \cdot 5$ & $1 \cdot 3$ & $1 \cdot 6$ & $29 \cdot 5$ & $1 \cdot 6$ & $3 \cdot 0$ \\
\hline
\end{tabular}

Table 1. Number of fin whale groups detected $\left(n_{j t}\right), \mathrm{km}$ of survey effort $\left(L_{j t}\right)$ and mean observed fin whale group size $\left(s_{j t}\right)$ in each year of cetacean line-transect surveys, by study stratum. Only whale groups $<4 \mathrm{~km}$ from the transect line and only survey effort during Beaufort sea state $\leq 5$ are included respectively; and $\beta_{d 4, j}$ is the stratum-specific trend coefficient, treated as a random variable from a normal hyper-distribution with hyperparameters $\beta_{D 4}$ and $\sigma_{D 4}$. We modelled trends as random effects rather than fixed effects under the assumption that population changes across strata are not fully independent, such that trend data from one region provide information about trends in all regions. This enables more efficient use of the data for estimating trend parameters, because all data are used to estimate the hyper-parameters and fewer parameters are required to generate stratum-specific trend estimates. $\gamma_{j t}$ is a random effect with mean zero and variance $\sigma_{d}^{2}$ that describes process variation in year-to-year density.

We also considered an equally general model in which the absolute rate of change in population density is decelerating (e.g. because of density dependence):

$D_{j t}=\exp \left(\beta_{d 0}+\beta_{d k}\left(\right.\right.$ strata $\left.\left._{k}\right)+\beta_{d 4, j} \log (t)+\gamma_{j t}\right)$

Finally, we considered reduced models, such as all strata sharing the same intercept and/or slope coefficients, or exhibiting no growth trend (i.e. intercept-only models).

\section{Observation model}

The observation model links the state process to the observed data. Rearranging eqn 1 and treating the observed counts as a Poisson random variable:

$n_{j t} \sim \operatorname{Pois}\left(E\left[n_{j t}\right]\right)$

$E\left[n_{j t}\right]=\frac{2 \cdot L_{j t} \cdot c}{s_{j t} \cdot f_{j t}(0)} \cdot D_{j t}$

Poisson overdispersion is handled implicitly by including process error and overdispersion terms in other model components. The survey lengths $L_{j t}$ were considered to be measured without error (Table 1). Trackline detectability $\hat{c}$ has been measured empirically for fin whales (Barlow \& Forney 2007); it has an estimated mean of 0.92 with standard error of $0 \cdot 02$. We discuss parameters $f_{j t}(0)$ and $s_{j t}$ in more detail.

Parameter $\mathrm{f}(0)$. For data truncated at distance $w(4 \mathrm{~km})$, the detection pdf is (Buckland et al. 2001):

$f_{j t}(y)=\frac{g_{j t}(y)}{\int_{0}^{w} g_{j t}(y) d y}$,

where $g_{j t}(y)$ is the detection function, and $g_{j t}(0)$ is 1 , so that

$f_{j t}(0)=\frac{1}{\int_{0}^{w} g_{j t}(y) d y}$.

Basedon previous analyses in our case study system (Barlow \& Forney 2007), we assume a half-normal detection function for $g_{j t}(y)$ :

$g_{j t}(y)=\exp \left(\frac{-y^{2}}{2 \sigma_{h}^{2}}\right)$

where $h$ denotes half-normal parameters. We estimated $\sigma_{h}$ and hence $f_{j t}(0)$ separately for each observation $i$ as a function of detection-specific covariates (see Marques \& Buckland (2004), for theoretical development of covariate use in the detection function). The most general covariate models we considered were:

$\sigma_{h, i}=\exp \left[\beta_{h 0}+\beta_{h 1}\left(\operatorname{rainFog}_{i}\right)+\beta_{h k}\left(\right.\right.$ strata $\left.\left._{k, i}\right)+\eta_{t, i}\right]$, and

$\sigma_{h, i}=\exp \left[\beta_{h 0}+\beta_{h 1}\left(\operatorname{rainFog}_{i}\right)+\beta_{h k}\left(\operatorname{strata}_{k, i}\right)+\beta_{h k}\left(\operatorname{ship}_{k, i}\right)\right]$,

where $\beta_{h 0}$ is the intercept; $\beta_{h 1}$ is the coefficient for rainFog; $\beta_{h k}$ for $k=2,34$, are fixed effect coefficients for binary stratum variables $\mathrm{SC}, \mathrm{CC}$ and $\mathrm{NC}$, respectively; $\beta_{h k}$ for $k=5,6$ are fixed effect coefficients for binary ship variables David Starr Jordan and McArthur; and $\eta_{t, i}$ is a random effect for year $t: \eta_{t} \sim \operatorname{Normal}\left(0, \sigma_{\sigma}\right)$. Year and ship variables were not included in the same models because they were largely confounded (data in a particular year were sometimes all from the same vessel). Reduced models included subsets of these variables but always included rainFog, based on model selection results of 
previous analyses (Barlow \& Forney 2007; Barlow 2010). For each $j, t$ group, the estimate $\hat{f}_{j t}(0)$ was calculated as the mean of all $\hat{f}_{i}(0)$ within stratum $j$ and time $t$.

Group size. For mean group size $s_{j t}$, Barlow \& Forney (2007) used means of the raw group size data in each $j, t$ group as point estimates. If detection distance increases with group size, this can potentially bias detectability estimates (Buckland et al. 2001), but we assumed this not to be problematic for fin whales within the 4-km truncation distance, given their conspicuous detection cues (e.g. large size and blows) and occurrence almost always in very small groups ( $86 \%$ of groups contained 1-3 animals). Zerbini et al. (2006) also found empirically that fin whale group size did not affect detection distance. Even so, while raw data means may provide good estimates of $s_{j t}$ for $j, t$ with reasonably large sample sizes, many of the $j, t$ have relatively few observations (e.g. $<5$ or 10 , Table 1); sample means in these cases may not always be good estimates of $s_{j t}$. Better and more precise estimates can be obtained treating observed group sizes $\left(s . o b s_{i}\right)$ as random variables and estimating statistical distribution parameters. We assumed a generalized Poisson distribution (Famoye 1993) for group size, with expected values modelled as a function of covariates. Like our population density models, the most general group size models considered strata effects and both exponential and decelerating growth trends. To be clear, we actually modelled 's.obs $s_{i}-1$ ' because all observed group sizes are positive integers. Thus,

$\left(\operatorname{s.obs}_{i}-1\right) \sim \operatorname{genPois}\left(\lambda_{j t}, \alpha_{t}\right)$,

Where $\alpha_{t}$ is a time-dependent random dispersion parameter (normally distributed with mean $\alpha$ and variance $\sigma_{\alpha}^{2}$ ) that implies overdispersion when $>0$. For exponential growth, the full model is:

$\lambda_{j t}=\exp \left(\beta_{s 0}+\beta_{s k}\left(\right.\right.$ strata $\left.\left._{k}\right)+\beta_{s 4, j} t+\delta_{j t}\right)$

$\beta_{s 4, j} \sim \operatorname{Norm}\left(\beta_{S 4}, \sigma_{S 4}\right)$,

$\delta_{j t} \sim \operatorname{Normal}\left(0, \sigma_{s}\right)$

where $s$ denotes a group size parameter; $S$ denotes a group size hyperparameter; $\beta_{s 0}$ is an intercept; $\beta_{s k}$ for $k=1,2,3$, are fixed effect coefficients for binary stratum variables $\mathrm{SC}, \mathrm{CC}$ and $\mathrm{NC}$, respectively; $\beta_{s 4, j}$ are random trend coefficients from a normal hyper-distribution with mean $\beta_{S 4}$ and variance $\sigma_{S 4}^{2}$; and $\delta_{j t}$ are random effects with mean zero and variance $\sigma_{s}^{2}$ to describe process variance. For decelerating growth, the model is:

$\lambda_{j t}=\exp \left(\beta_{s 0}+\beta_{s k}\left(\right.\right.$ strata $\left.\left._{k}\right)+\beta_{s 4, j} \log (t)+\delta_{j t}\right)$.

The expected value for group size for each $j$, $t$ (i.e. $\left.s_{j t}\right)$ is $\lambda_{j t}+1$, and the variance for the generalized Poisson is $\left(\lambda_{j t}\right) \cdot\left[1+\alpha_{t}\left(\lambda_{j t}\right)\right]^{2}$. Reduced models (e.g. intercept only, shared intercepts and shared slopes) were also evaluated.

\section{Parameter estimation}

Parameter estimation was conducted using a Bayesian MCMC approach in WinBUGS 1.4.3 (Lunn et al. 2000; Spiegelhalter et al. 2007). See Appendices S1 and S2 (Supporting Information) for WinBUGS code and likelihood expressions. Vague priors were used on all parameters except for $c$, for which the prior distribution was informative $[\beta(157,13 \cdot 5)]$, corresponding to empirical estimates of mean $=0.92$ with standard error $=0.02$ (Barlow \& Forney 2007) Normal priors with mean $=0$ and large variance (e.g. 10000$)$ were used for intercept and slope coefficients (e.g. $\beta$ s). Uniform $(0,100)$ distributions were used for $\alpha$ and standard deviations of random effects $\left(\sigma_{D 4}, \sigma_{d}, \sigma_{S 4}, \sigma_{s}, \sigma_{\sigma}\right)$. For each model, MCMC runs consisted of two chains with a burn-in of 10000 samples, and a posterior distribution based on 30000 samples for each chain (60 000 samples total); this was generally sufficient to achieve low Monte Carlo errors $(<5 \%$ of MCMC sample standard deviation) for key parameters.

\section{Model selection and model averaging}

There is no consensus on how to address Bayesian model uncertainty or conduct multi-model inference (see overview by Link \& Barker 2010). We used Deviance Information Criteria (DIC), which allows for selection of Bayesian hierarchical models (Spiegelhalter et al. 2002). DIC is defined as $\bar{D}+p D=\hat{D}+2 p D$, where $\bar{D}$ is the posterior mean model deviance, $\hat{D}$ is the model deviance for the posterior parameter means, and $p D$ (interpreted as the effective number of parameters) is $\bar{D}-\hat{D}$. DIC can be problematic in certain situations (Spiegelhalter et al. 2007), but it is easily calculated from MCMC output (and is available as a standard output in WinBUGS), and it remains the standard tool for hierarchical model selection as evidenced by its widespread use and coverage by recent reviews and textbooks (e.g. Cressie et al. 2009; Congdon 2010; Link \& Barker 2010). The number of possible joint models (i.e. combinations of density, detection and group size model components) was too large to practically evaluate in entirety, so we took a modular approach to model selection. We first conducted model selection separately for detectability (distance data) and group size components of the model (i.e. treated them as separate models). Detectability and group size submodels with $\triangle \mathrm{DIC}$ (difference in DIC between that of model $k$ and the lowest DIC) $<4$ were subsequently considered in joint models of detectability, group size and density. For joint models in which both group size and density were modelled as time dependent, the time parameter in each component was specified with the same general form (e.g. random time effect, exponential trend or decelerating trend). Process error terms $\left(\gamma_{j t}\right.$ and $\delta_{j t}$ ) were not included during model selection, because most models fit the data equally well when process error terms were included, such that important predictor variables could not be properly identified (i.e. unexplained variance in the absence of useful predictors is just incorporated in the process error terms). Final joint models with $\Delta \mathrm{DIC}<2$ were deemed strong candidates for a 'best' model (Burnham \& Anderson 2002; Spiegelhalter et al. 2002). We conducted Bayesian model averaging of these top models to make inference about trends and estimate abundance in survey years in the face of model uncertainty. For derived model parameters (e.g. abundance), we generated model-averaged posterior distributions by sampling parameter estimates from the posterior distributions of different models in proportion to their relative DIC weights, defined for model $k$ as:

$w_{k}=\frac{\exp \left(-\Delta_{k} / 2\right)}{\sum_{m=1}^{M} \exp \left(-\Delta_{m} / 2\right)}$,

where $\Delta_{k}$ refers to $\Delta$ DIC for model $k$, and $\Delta_{m}$ are the $\Delta$ DIC values for all candidate models. These weights are considered analogues to AIC model weights (Burnham \& Anderson 2002), and although not theoretically justified, this approach has been applied in previous analyses and shown to be useful for prediction (e.g. Brooks, in Spiegelhalter et al. 2002; Wilberg \& Bence 2008; Jiao, Reid \& Smith 2009). 


\section{Prediction}

We used model-averaged posterior distributions to predict fin whale abundance estimates out to 2016. Beyond this time horizon ( 8 years from most recent survey, 2008), MMPA policy considers abundance estimates too out of date to be used for management decision-making in terms of setting allowable mortality limits for marine mammals (NMFS 2005). Within this time frame, allowable mortality estimates may benefit from abundance projections (especially as a precautionary measure for declining populations), rather than remaining fixed according to the most recent estimates. Process model parameters, $\beta_{d}$ 's and $\sigma_{d}$, were drawn 100000 times with replacement from the joint model-averaged posterior distributions. Fin whale abundance in each $j$ at all future $t$ (2009 through 2016) was calculated for each MCMC sample from the deterministic parameter estimates $\left(\beta_{d} \mathrm{~s}\right)$ plus a unique process error term for each $j, t$ that was randomly drawn from a normal distribution with mean 0 and variance $\sigma_{d}^{2}$. This generated distributions for predicted $D_{j t}$ which were multiplied by $A_{j}$ to estimate $N_{j t}$ and summed across strata to estimate $N_{t}$. Estimates reflected both parameter estimation uncertainty and process variance. To demonstrate the usefulness of this, we also compared these to projected estimates that ignore process error.

\section{Results}

\section{MODEL SELECTION}

There were four detectability submodels and 13 group size submodels with enough support to be considered for inclusion in the set of joint detectability, group size, and density models (Tables 2 and 3). Based on DIC, the top nine group size submodels included a time-dependent rather than constant overdispersion parameter (i.e. $\alpha_{t}$ vs. $\alpha$ ); we took this as sufficient evidence to conclude that group size overdispersion should be modelled as a time-dependent parameter.

Model selection results for joint models are summarized in Table 4. All candidate models $(\Delta \mathrm{DIC} \leq 4)$ included parameters strata $\times T_{\text {pow }}$ or strata $\times T$ for the density component, providing strong evidence that fin whale density and abundance has increased with time and that rates of increase have varied by stratum. The most competitive models $(\Delta \mathrm{DIC} \leq 2)$ suggested that increases have slowed through time. All but one candidate model suggested that variation in detectability was best described by the binary rainFog variable + random year effects. The best descriptors of group size variation were less certain (top joint models included intercept only, $T_{\text {pow }}$, and strata $\times T_{\text {pow }}$ models for group size), but in general, temporal trend models received the most support.

The relative importance of various predictors of detectability and group size differed in the joint models from stand-alone detection and group size submodels (compare Tables 2 and 3 with Table 4). For example, the most supported submodel of detectability included ship, and the rainFog-only model was more strongly supported than the rainFog + year model. In contrast, rainFog + year was the most strongly supported of the joint models, and none of the candidate joint models included ship, suggesting that probable ship effects (Zerbini et al. 2006; Barlow \& Forney 2007) were subsumed by year terms. For group size, some of the candidate submodels
Table 2. Model selection results for detectability models fit to pooled distance data from fin whales, blue whales and killer whales. Model variables included (rainFog and ship are fixed effects; year $t$ is a random effect). $\bar{D}$ and $\hat{D}$ are mean model deviance and model deviance at the parameter means, respectively. $p D$ is the effective number of parameters. Models with $\triangle \mathrm{DIC}<4$ (in bold) were considered for inclusion in combined models of detectability, group size and density (Table 4)

\begin{tabular}{|c|c|c|c|c|c|}
\hline Model & $\bar{D}$ & $\hat{D}$ & $p D$ & DIC & $\Delta \mathrm{DIC}$ \\
\hline RainFog & $1322 \cdot 3$ & $1320 \cdot 3$ & $2 \cdot 0$ & $1324 \cdot 2$ & $1 \cdot 1$ \\
\hline RainFog + ship & $1319 \cdot 4$ & $1315 \cdot 8$ & $3 \cdot 7$ & $1323 \cdot 1$ & $\mathbf{0} \cdot \mathbf{0}$ \\
\hline RainFog $+t$ & $1321 \cdot 1$ & $1316 \cdot 6$ & 4.5 & $1325 \cdot 5$ & $2 \cdot 4$ \\
\hline RainFog + strata & $1323 \cdot 5$ & $1318 \cdot 8$ & $4 \cdot 8$ & $1328 \cdot 3$ & $5 \cdot 2$ \\
\hline RainFog + ship + strata & $1318 \cdot 5$ & $1312 \cdot 4$ & $6 \cdot 1$ & $1324 \cdot 6$ & 1.5 \\
\hline RainFog $+t+$ strata & $1321 \cdot 8$ & $1315 \cdot 1$ & $6 \cdot 7$ & $1328 \cdot 5$ & $5 \cdot 4$ \\
\hline
\end{tabular}

DIC, Deviance Information Criteria.

Table 3. Model selection results for fin whale group size. Models are divided into those with constant $(\alpha)$ and time-dependent $\left(\alpha_{t}\right)$ overdispersion. Model variables include strata (categorical, fixed effect), $t$ (categorical, random year effect), $T$ (exponential time trend) and $T_{\text {pow }}$ (asymptotic time trend). Models denoted 'strata $\times T$ ' and 'strata $\times T_{\text {pow }}$ ' imply a separate trend (treated as a random effect) for each stratum. $\bar{D}$ and $\hat{D}$ are mean model deviance and model deviance at the parameter means, respectively. $p D$ is the effective number of parameters. Models in bold font have $\Delta \mathrm{DIC}<4$, but only the $\alpha_{t}$ models were considered for inclusion in combined models of detectability, group size and density (Table 4)

\begin{tabular}{|c|c|c|c|c|c|}
\hline Model & $\bar{D}$ & $\hat{D}$ & $p D$ & DIC & $\Delta \mathrm{DIC}$ \\
\hline \multicolumn{6}{|l|}{ Constant $\alpha$ models } \\
\hline Intercept only & $774 \cdot 9$ & $772 \cdot 9$ & $2 \cdot 0$ & $776 \cdot 8$ & $7 \cdot 1$ \\
\hline Strata & $772 \cdot 9$ & $767 \cdot 8$ & $5 \cdot 0$ & $777 \cdot 9$ & $8 \cdot 2$ \\
\hline$t$ & $771 \cdot 2$ & $766 \cdot 0$ & $5 \cdot 2$ & $776 \cdot 4$ & $6 \cdot 7$ \\
\hline$T$ & $772 \cdot 3$ & $769 \cdot 2$ & $3 \cdot 1$ & $775 \cdot 3$ & $5 \cdot 6$ \\
\hline$T_{\text {pow }}$ & $772 \cdot 2$ & $769 \cdot 2$ & $2 \cdot 9$ & $775 \cdot 1$ & $5 \cdot 4$ \\
\hline Strata $+t$ & $765 \cdot 2$ & $756 \cdot 3$ & 8.9 & $774 \cdot 1$ & $4 \cdot 4$ \\
\hline Strata $+T$ & 766.6 & $760 \cdot 7$ & 5.9 & $772 \cdot 5$ & $2 \cdot 8$ \\
\hline Strata $+T_{p o w}$ & $767 \cdot 1$ & $761 \cdot 2$ & 5.9 & $773 \cdot 0$ & $3 \cdot 3$ \\
\hline Strata $\times T$ & $764 \cdot 3$ & $755 \cdot 8$ & 8.5 & $772 \cdot 9$ & $3 \cdot 2$ \\
\hline Strata $\times T_{p o w}$ & 763.8 & $755 \cdot 2$ & 8.6 & $772 \cdot 4$ & $2 \cdot 7$ \\
\hline \multicolumn{6}{|c|}{ Time-dependent $\alpha_{t}$ models } \\
\hline Intercept only & 764.8 & $758 \cdot 1$ & 6.8 & $771 \cdot 6$ & 1.9 \\
\hline Strata & 765.9 & $756 \cdot 2$ & $9 \cdot 7$ & $775 \cdot 6$ & $5 \cdot 9$ \\
\hline$t$ & $762 \cdot 3$ & 752.5 & $9 \cdot 7$ & 772.0 & $2 \cdot 3$ \\
\hline$T$ & 761.9 & $754 \cdot 2$ & $7 \cdot 7$ & $769 \cdot 7$ & 0.0 \\
\hline$T_{p o w}$ & $762 \cdot 3$ & $754 \cdot 6$ & $7 \cdot 7$ & $770 \cdot 0$ & $0 \cdot 3$ \\
\hline Strata $+t$ & $758 \cdot 2$ & $744 \cdot 4$ & $13 \cdot 8$ & $772 \cdot 0$ & $2 \cdot 3$ \\
\hline Strata $+T$ & $759 \cdot 9$ & 748.9 & 11.0 & 771.0 & $1 \cdot 3$ \\
\hline Strata $+T_{p o w}$ & $760 \cdot 9$ & $750 \cdot 1$ & $10 \cdot 8$ & 771.8 & $2 \cdot 1$ \\
\hline Strata $\times T$ & 757.9 & $\mathbf{7 4 4} \cdot 7$ & $13 \cdot 2$ & $771 \cdot 1$ & $1 \cdot 4$ \\
\hline Strata $\times T_{p o w}$ & $758 \cdot 1$ & $745 \cdot 2$ & $12 \cdot 9$ & $771 \cdot 0$ & $1 \cdot 3$ \\
\hline
\end{tabular}

included random year effects $(t)$, which did not appear in any of the candidate joint models, and $T$ models (vs. $T_{\text {pow }}$ ) generally received more support in the stand-alone group size models than in the joint models. These differences are attributable to the influence of the count data model component on estimating parameters that also occur in detectability or group size model components. A model that most parsimoniously 
Table 4. Model selection results for combined models of fin whale detectability $(f)$, group size $(s)$ and density $(D)$. Models with $\Delta$ DIC $\leq 4$ are shown. Models in bold font $(\Delta \mathrm{DIC} \leq 2)$ were used in model averaging. Model variables for $f$ and $s$ are as in Tables 2 and 3 . All models here assume time-dependent overdispersion for group size data and simple Poisson variation for count data. Density model variables include strata (categorical, fixed effect), $T$ (exponential time trend) and $T_{\text {pow }}$ (decelerating time trend). Models denoted 'strata $\times T$ ' and 'strata $\times T_{p o w}$ ' imply a separate trend (random effect) for each stratum. $\overline{D e v}$ and $D \hat{e} v$ are mean model deviance and model deviance at the parameter means, respectively. $p D$ is the effective number of parameters. $w_{k}$ are DIC model weights, scaled to sum to 1 across models here (weights in parentheses are scaled to sum to 1 across models with $\Delta \mathrm{DIC} \leq 2)$

\begin{tabular}{|c|c|c|c|c|c|c|}
\hline Model & $\overline{D e v}$ & $D \hat{e v}$ & $p D$ & DIC & $\Delta \mathrm{DIC}$ & $w_{k}$ \\
\hline$f($ rainfog $) s\left(T_{\text {pow }}\right) D\left(\right.$ strata $\left.\times T_{\text {pow }}\right)$ & $2230 \cdot 1$ & $2212 \cdot 2$ & $17 \cdot 9$ & $2247 \cdot 9$ & $3 \cdot 6$ & $0 \cdot 05$ \\
\hline$f($ rainfog $+t) s() D.($ strata $\times T)$ & $2227 \cdot 7$ & $2207 \cdot 2$ & $20 \cdot 5$ & $2248 \cdot 2$ & $3 \cdot 9$ & $0 \cdot 04$ \\
\hline$f($ rainfog $+t) s(T) D($ strata $\times T)$ & $2225 \cdot 1$ & $2203 \cdot 3$ & $21 \cdot 8$ & $2246 \cdot 9$ & $2 \cdot 6$ & $0 \cdot 08$ \\
\hline$f($ rainfog $+t) s($ strata $+T) D($ strata $\times T)$ & $2222 \cdot 0$ & $2197 \cdot 5$ & $24 \cdot 5$ & $2246 \cdot 6$ & $2 \cdot 3$ & $0 \cdot 09$ \\
\hline$f($ rainfog $+t) s($ strata $\times T) D($ strata $\times T)$ & $2222 \cdot 4$ & $2193 \cdot 6$ & $26 \cdot 8$ & $2247 \cdot 2$ & $2 \cdot 9$ & $0 \cdot 07$ \\
\hline$f($ rainfog $+t) s() D.\left(\right.$ strata $\left.\times T_{p o w}\right)$ & $2225 \cdot 1$ & $2204 \cdot 5$ & $20 \cdot 6$ & $2245 \cdot 7$ & $1 \cdot 4$ & $0 \cdot 14(0 \cdot 25)$ \\
\hline$f($ rainfog $+t) s\left(T_{\text {pow }}\right) D\left(\right.$ strata $\left.\times T_{p o w}\right)$ & $2222 \cdot 7$ & $2201 \cdot 0$ & $21 \cdot 7$ & $2244 \cdot 3$ & 0.0 & $0.29(0.49)$ \\
\hline$f($ rainfog $+t) s\left(\right.$ strata $\left.+T_{\text {pow }}\right) D\left(\right.$ strata $\left.\times T_{\text {pow }}\right)$ & $2221 \cdot 9$ & $2197 \cdot 2$ & $24 \cdot 6$ & $2246 \cdot 5$ & $2 \cdot 2$ & $0 \cdot 10$ \\
\hline$f($ rainfog $+t) s\left(\right.$ strata $\left.\times T_{\text {pow }}\right) D\left(\right.$ strata $\left.\times T_{\text {pow }}\right)$ & $2219 \cdot 0$ & $2192 \cdot 4$ & $26 \cdot 6$ & $2245 \cdot 6$ & $1 \cdot 3$ & $0 \cdot 15(0 \cdot 26)$ \\
\hline
\end{tabular}

describes all data will be favoured over one that, say, provides the best fit to distance data but a poor fit to count data.

\section{MODEL-AVERAGED PARAMETER ESTIMATES ABUNDANCE AND TRENDS}

Deviance Information Criteria-weighted posterior distribution summaries for density and detectability parameters are in Appendix S3 (Supporting Information). The posterior mean estimate of the derived parameter $f_{j t}(0)$ varied from $0 \cdot 34$ to 0.49 across year and rainFog conditions (Fig. 2), and mean effective strip width $\left(1 / f_{j t}(0)\right)$ varied from $2 \cdot 2$ to $2 \cdot 9 \mathrm{~km}$; these values are similar to those previously reported for fin whales (Barlow \&
Forney 2007; Barlow 2010). We did not summarize modelaveraged group size parameters, because different models contained different parameters. However, the top two joint models (Table 4) provide support for time-dependent variation in fin whale group size, with trend coefficients in these individual models both suggesting an increase through time (see Appendix S4, Supporting Information for posterior summaries of individual model parameters). Model-averaged mean group size estimates (derived parameters) across the $j, t$ ranged from 1.6 to $5 \cdot 9$ (mean $=2 \cdot 3)$. The maximum of these was for the SC stratum in 2001, when only a single group of 29.5 whales (mean of multiple observers' estimates) was recorded. The modelled vs. observed estimate of group size in this case illustrates the
1991

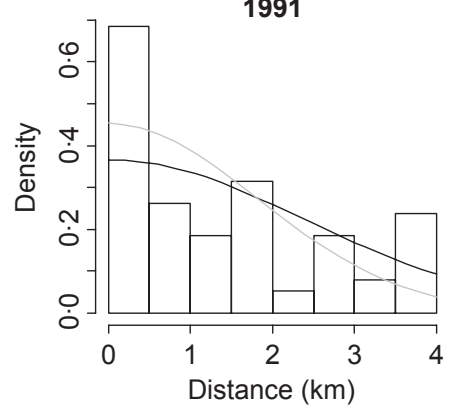

2001

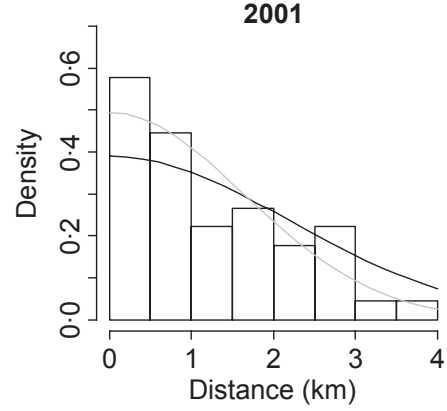

1993

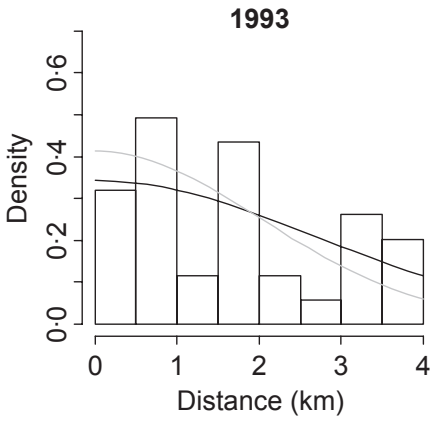

2005

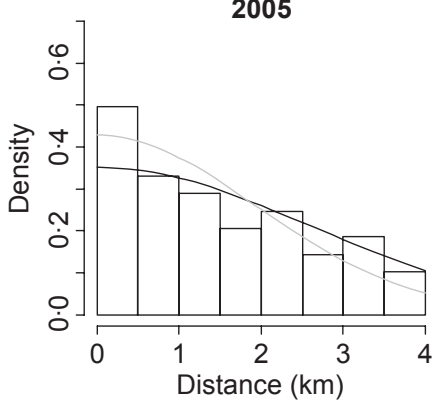

1996

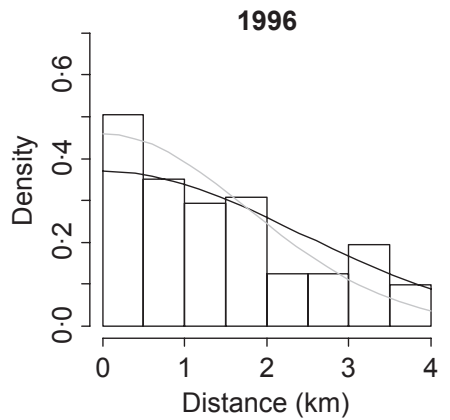

2008

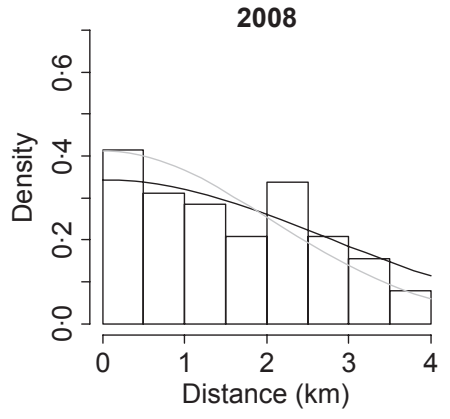

Fig. 2. Histograms of detection distances (truncated at $4 \mathrm{~km}$ ) by year, and mean $\hat{f}(y)$ by year and rainFog condition, for pooled observations of fin whales, blue whales and killer whales (sample size $=507$ ). Grey $\hat{f}(y)$ lines represent rainy or foggy conditions (binary rainFog variable $=1$ ). 
usefulness of the hierarchical shrinkage estimators. The strong relation between fitted and observed values, and the absence of temporal pattern in the group size residual plots (Fig. 3, left), suggests a reasonable fit of the model to the data. However, there was a tendency to overestimate group size slightly, particularly for the smallest groups, largely due to the influence of the extreme observation (29.5). Mean relative bias [(observed-fitted)/fitted] in group size across all j,t was $+10 \%$ (i.e. group size underestimated) but was $-8.5 \%$ (overestimated) excluding the extreme observation.

The model-averaged posterior distributions for density trend parameters provide strong evidence of an overall increase in abundance throughout the study area since the early-mid 1990s. Posterior estimates of total abundance across California strata increased by a median of $124 \%(90 \%$ credible interval: 40-265\%) between 1991 and 1996 (Fig. 4). Across all strata, median increase in total abundance was 51\% (90\% CRI: 4-113\%) between 1996 and 2008, with median annual growth rate $\left(\lambda_{t}=N_{t}+{ }_{1} / N_{t}\right)$ estimates calculated from trend coefficients declining from $\lambda_{1996}=1.071(90 \%$ CRI: $1 \cdot 028-1 \cdot 112)$ to $\lambda_{2007}=1 \cdot 035(90 \%$ CRI: $1 \cdot 017-1 \cdot 055)$

(Fig. 5). On a stratum-specific basis, mean population density and abundance has consistently been greatest but not neces-
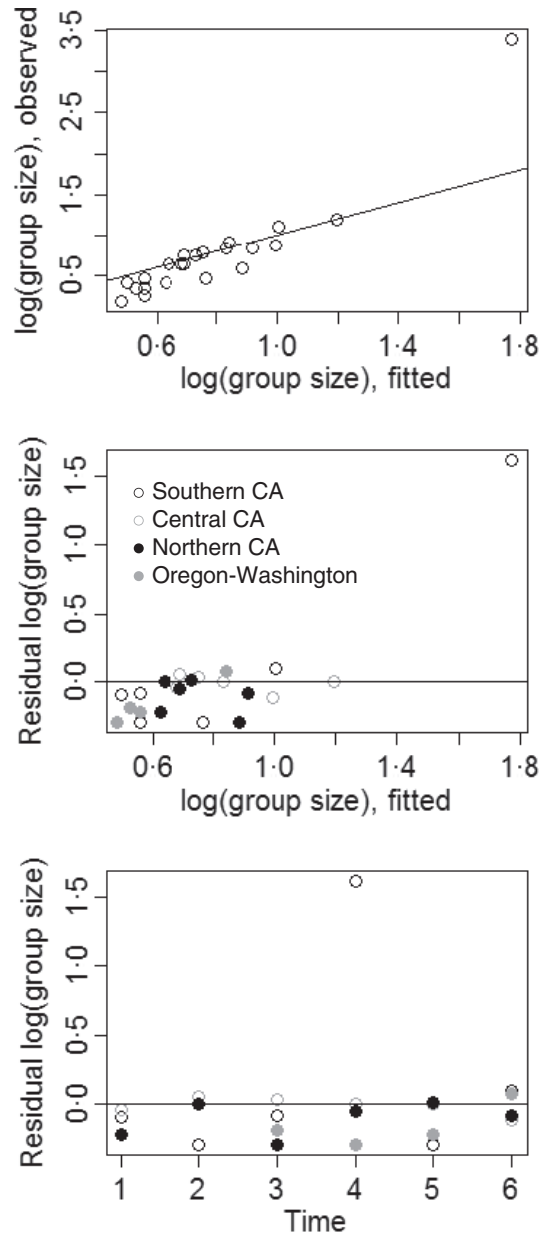

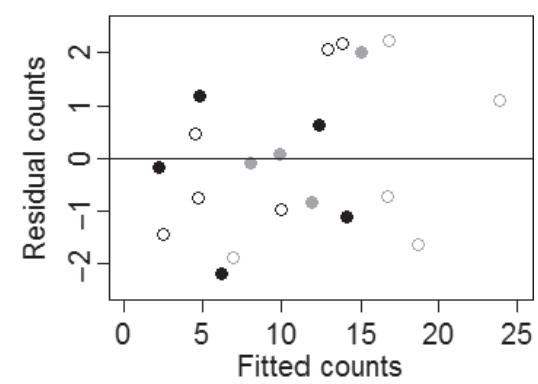

sarily increasing in the $\mathrm{CC}$ stratum, with mean population increases through time having been driven by increases in other strata (Fig. 6). Under the MMPA, the 20th percentile estimate of abundance is used for estimating management thresholds for incidental take by fisheries (NMFS 2005); these abundance estimates are included in Appendix S5 (Supporting Information). Plots of fitted vs. observed fin whale counts, and associated residual plots (Fig. 3, right), suggest that count data were well described by this model, with no residual overdispersion.

\section{PREDICTED FUTURE ABUNDANCE}

Assuming no change in the underlying population dynamics process, fin whale abundance in the study area beyond 2008 is expected to continue increasing at a mean rate of about $3 \%$ per year on average, although year-to-year abundance should rise and fall according to random process variation. Ignoring process variance, uncertainty in future abundances beyond 2008 simply depends on uncertainty in the 2008 abundance estimate and in the trend estimates because of sampling error; this is depicted by the solid prediction lines in Fig. 7. Accounting for process variance, uncertainty in future abundance
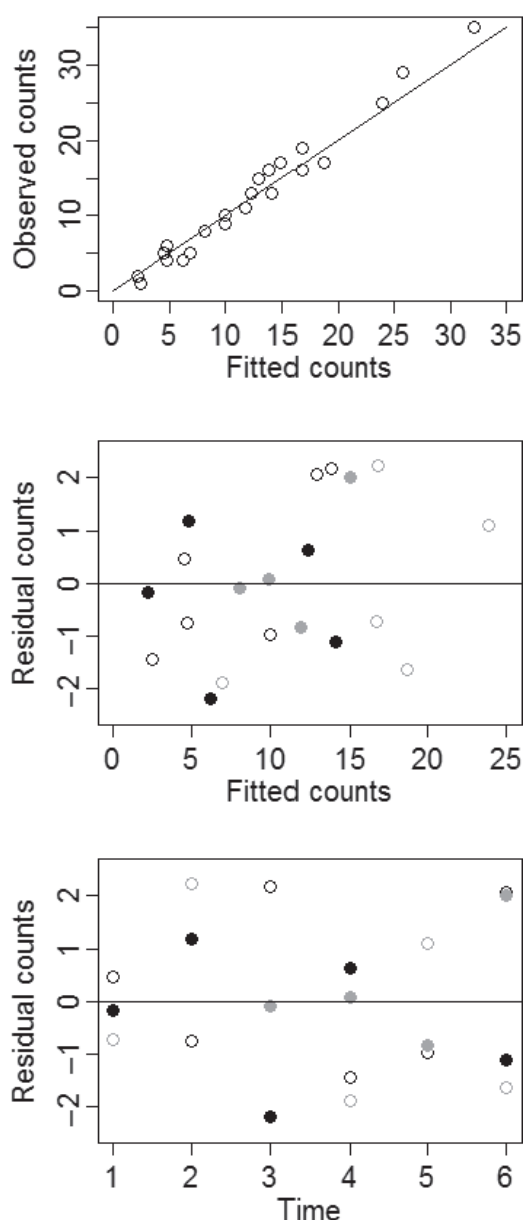

Fig. 3. Residuals (observed-fitted values; on $y$-axis) for mean group size (left panels) and counts of fin whale groups (right panels). Group size data are represented on $\log$ scale because of an outlier. Points are coded by stratum. Diagonal lines in top panels represent $1: 1$ relationship. 


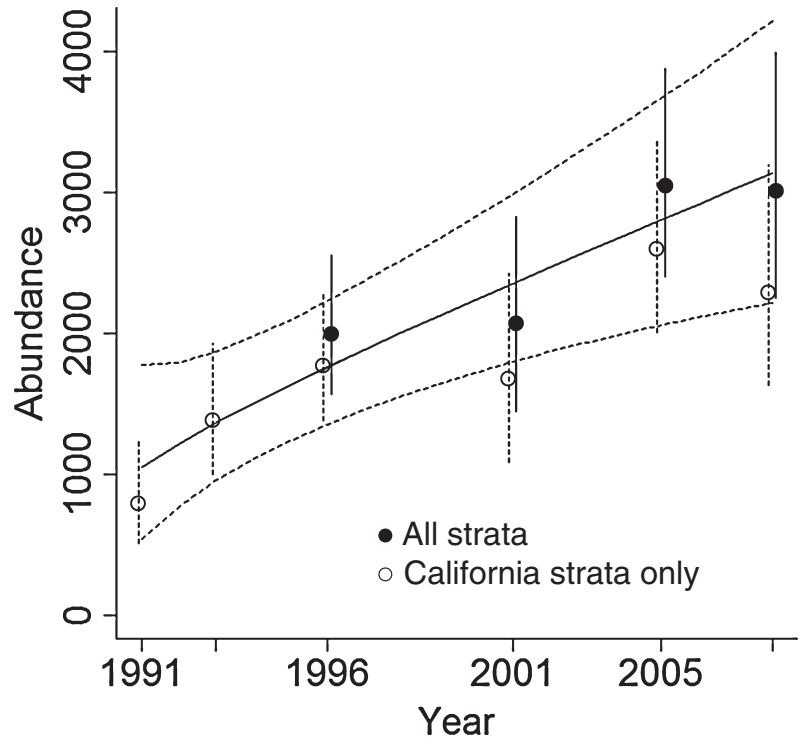

Fig. 4. Fin whale abundance and trend estimates during survey years (medians with $90 \%$ Bayesian credible intervals). California strata (Southern, Central and Northern) were surveyed in all years. All strata (California plus Oregon-Washington) were surveyed from 1996 onward. Fitted trend estimates are for all strata.
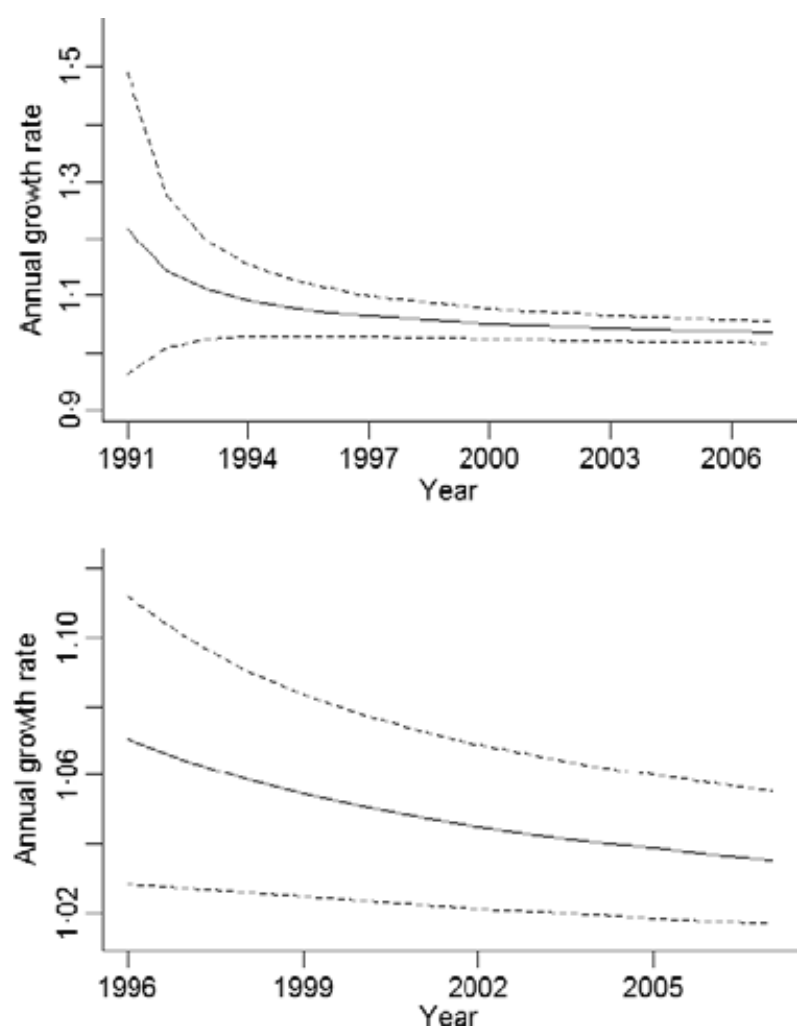

Fig. 5. Posterior mean and $90 \%$ credible interval estimates for annual population increase $\left(N_{t}+{ }_{1} / N_{t}\right)$ of fin whales in the California Current through time, calculated from trend coefficient estimates. Top panel shows estimates from $t=1991$ though 2007. For larger scale, the bottom panel shows the same estimates from 1996 through 2007, the period when survey data came from all strata.

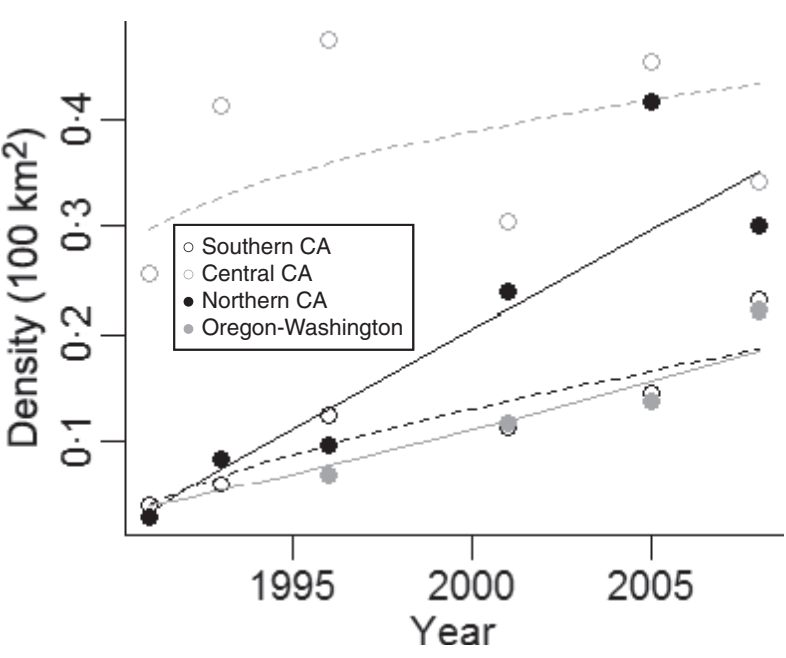

Fig. 6. Posterior mean fin whale density and density trend estimates (per $100 \mathrm{~km}^{2}$ ) by survey year and stratum.

estimates is greater (see dotted lines in Fig. 7), although there is still high probability that the overall mean trend through time will be positive. In this analysis, 20th percentile estimates of future abundance are almost identical whether or not process variation is considered in the prediction model, although the same is not true for posterior median estimates or $90 \%$ credible intervals.

\section{Discussion}

Estimating population abundance trends is central to questions in ecology, conservation and management, yet only very recently have methods been developed for estimating both trends and abundance estimates directly within a single frame-

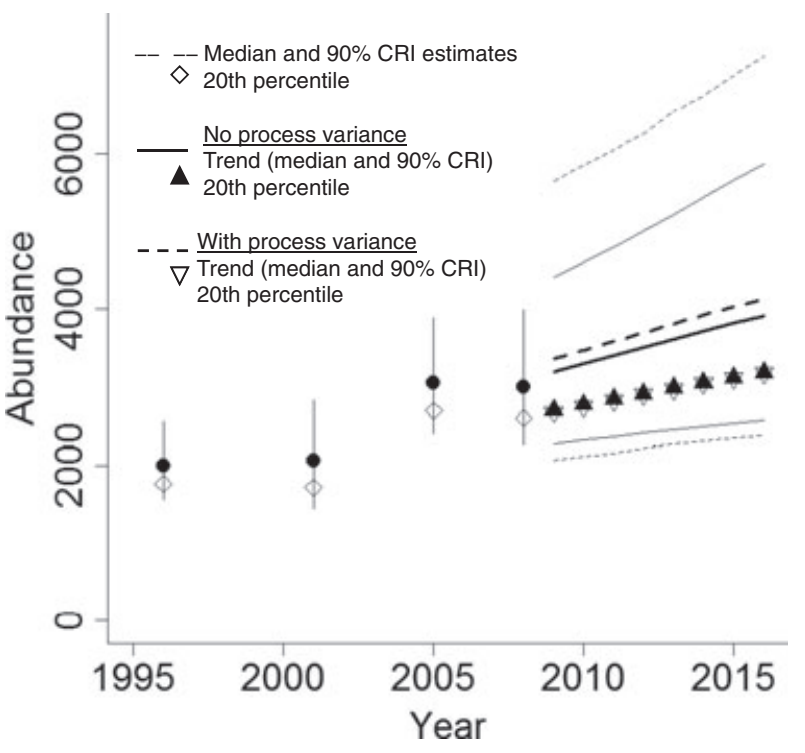

Fig. 7. Bayesian posterior estimates of fin whale abundance for the entire study area during 1996-2008 surveys and projected 8 years beyond 2008, based on fitted trend model. 
work and explicitly from the imperfect observation process (e.g. Kéry et al. 2009; Kéry \& Royle 2010). To our knowledge, no such method has yet been demonstrated using data collected from distance sampling methods, apart from the simpler case of comparing two abundance estimates (e.g. Buckland et al. 2001; Gerrodette et al. 2011) or conducting post hoc trend fitting to individual distance-based abundance estimates (Thomas, Burnham \& Buckland 2004). The approach we used fits within a general hierarchical model framework (sensu Royle \& Dorazio 2008; Kéry \& Royle 2010) and would thus easily accommodate other specifications of the state or observation process, with particularly straightforward extension to point (as opposed to line-transect) distance sampling. Compared to a post hoc approach, the hierarchical method is more efficient for the researcher (many abundance analyses are replaced by a single analysis), more flexible (e.g. allows for random effects), useful for prediction (because process error is estimated explicitly) and yields improved parameter estimates. For example, CVs in our total abundance estimates were $0 \cdot 15$ and $0 \cdot 18$ in 2005 and 2008, compared with 0.25 and $0 \cdot 26$, respectively, reported by Barlow (2010), who used the same data set to estimate abundance separately in both years.

Improved parameter estimates are attributable in part to the use of shared information and hierarchical shrinkage estimators to estimate not just detectability but also other parameters such as group size and process variance terms, all of which affect abundance estimates. Abundance estimates are also made more precise by formulating the problem as a trend model (effectively, fewer parameters are estimated) with a joint posterior distribution in which multiple data sets (in our case counts, group sizes and detection distances) all influence the estimates of parameters shared across individual likelihood functions. Goodman (2004) similarly described the benefits of joint likelihoods for estimating population parameters. Thus, parameter estimates that reduce overall model deviance are considered the most probable, irrespective of their influence on deviance of particular model components. This may help reduce model uncertainty via buffering model selection from the effects of random sampling error.

Of course, these improved estimates also depend on the validity of an increased set of assumptions in the hierarchical trend model that are not imposed when abundance is estimated separately each year and when bootstrapping is used to estimate variances. Such assumptions include the functional form of the trend model and distributional assumptions about the count process (e.g. Poisson, generalized Poisson, negative binomial) and random effects (e.g. normal, log-normal). Moreover, while the Bayesian method implicitly deals with correlated sampling error, it does not account for correlated process error typical of time-series data (i.e. temporal autocorrelation). We could not estimate this potential error source because of the relatively sparse data set (data from only 6 years), but we would expect little residual correlation because of the time elapsed between data points (several years) and because our count data come from a spatially open system such that successive abundance estimates reflect movement in and out of the study area as well as in situ dynamics.
Fin whale populations worldwide were depleted by commercial whaling in the 20th century (NMFS 2006). Our model estimates suggest that fin whale abundance has steadily increased off the west coast of the lower continental United States since at least as early as 1991, although given the decelerating increase and point estimates suggesting possible lower abundance in 2008 than 2005, more data will be needed to discern whether the increasing trend will continue. Model projections into the future suggest high probability of a continuing increase (Fig. 7), but this of course depends on the factors responsible for past trends remaining unchanged over the next decade. As this model is empirical rather than mechanistic, those factors are unknown to the present analysis.

The rapid abundance increases in the study area during the early 1990s (i.e. the difference in 1991 and 1993 mean abundance estimates corresponds to an average of $32 \%$ increase per year) are not explainable by in situ population growth alone, given maximum annual growth rates likely for large cetaceans (Wade 1998; Zerbini et al. 2006). Rather, dispersal of new animals into the study area is likely to have occurred during this time period. The only other published study of fin whale trends in the North Pacific showed strong evidence of population growth at $4.8 \%$ per year $(95 \% \mathrm{CI}=4 \cdot 1-5 \cdot 4 \%)$ for 2001-2003 (Zerbini et al. 2006), which is very similar to the trend-fit estimates of annual growth in our system during these years (i.e. $\lambda_{2001}=1 \cdot 048, \lambda_{2002}=1 \cdot 045$; Fig. 5). Little is currently known about fin whale population structure in the North Pacific, but our study area is near the southern limit of the summer and autumn distribution of the species as a whole (Mizroch et al. 2009). A large-scale northward shift in the distribution of blue whales $B$. musculus was seen in the North Pacific, possibly associated with an oceanographic regime change at the end of the 1990s (Calambokidis et al. 2009), and similar distribution changes may occur for fin whales. Fin whale increases in the early 1990s appeared to occur in all study strata, with highest densities and possibly the fastest increases occurring in the CC stratum (Fig. 6); this area supported high fin whale catches in the 20th century so may be a historically important area for fin whales (Mizroch et al. 2009). Since the mid 1990s, fin whale densities have fluctuated without obvious trends in waters off $\mathrm{CC}$, while increases have occurred in other strata, especially off $\mathrm{NC}$, perhaps signalling that fin whale densities in CC are reaching historical levels or at least current ecosystem limits.

\section{Acknowledgements}

We thank the marine mammal observers, cruise leaders, survey coordinators, officers and crew who worked long hours in difficult conditions to collect the data used in this report. Karin Forney was the Chief Scientist of the 2005 survey effort. We are grateful to T. Eguchi, T. Gerrodette, W. Perrin, O. Gimenez and the editor for their comments to improve the manuscript. Thanks to Jeff Laake and Len Thomas for some statistical advice.

\section{References}

Amstrup, S.C., McDonald, T.L. \& Manly, B.F.J. (2005) Handbook of CaptureRecapture Analysis. Princeton University, Princeton. 
Barlow, J. (2010) Cetacean abundance in the California Current estimated from a 2008 ship-based line-transect survey. NOAA Technical Memorandum NOAA-TM-NMFS-SWFSC-456.

Barlow, J. \& Forney, K.A. (2007) Abundance and the population density of cetaceans in the California Current ecosystem. Fishery Bulletin, 105, 509526

Barlow, J., Gerrodette, T. \& Forcada, J. (2001) Factors affecting perpendicular sighting distances on shipboard line-transect surveys for cetaceans. Journal of Cetacean Research and Management, 3, 201-212.

Borchers, D.L., Buckland, S.T. \& Zucchini, W. (2002) Estimating Animal Abundance. Springer, New York.

Buckland, S.T., Anderson, D.R., Burnham, K.P., Laake, J.L., Borchers, D.L. \& Thomas, L. (2001) Introduction to Distance Sampling. Oxford University, New York.

Buckland, S.T., Anderson, D.R., Burnham, K.P., Laake, J.L., Borchers, D.L. \& Thomas, L. (2004) Advanced Distance Sampling. Oxford University, New York.

Burnham, K.P. \& Anderson, D.R. (2002) Model Selection and Multimodel Inference, 2nd edn. Springer, New York.

Calambokidis, J., Barlow, J., Ford, J.K.B., Chandler, T.E. \& Douglas, A.B. (2009) Insights into the population structure of blue whales in the Eastern North Pacific from recent sightings and photographic identification. Marine Mammal Science, 25, 816-832.

Clark, J.S. (2007) Models for Ecological Data. Princeton University, Princeton.

Congdon, P.D. (2010) Applied Bayesian Hierarchical Methods. CRC, Boca Raton.

Cressie, N., Calder, C.A., Clark, J.S., Ver Hoef, J.M. \& Wikle, C.K. (2009) Accounting for uncertainty in ecological analysis: the strengths and limitations of hierarchical statistical modeling. Ecological Applications, 19, $553-570$.

Famoye, F. (1993) Restricted generalized poisson regression model. Communications in Statistics - Theory and Methods, 22, 1335-1354.

Gerrodette, T. \& Forcada, J. (2005) Non-recovery of two spotted and spinner dolphin populations in the eastern tropical Pacific Ocean. Marine Ecology Progress Series, 291, 1-21.

Gerrodette, T., Taylor, B.L., Swift, R., Rankin, S., Jaramillo-Legorreta, A.M. \& Rojas-Bracho, L. (2011) A combined visual and acoustic estimate of 2008 abundance, and change in abundance since 1997, for the vaquita, Phocoena sinus. Marine Mammal Science, 27, 79-100.

Goodman, D. (2004) Methods for joint inference from multiple data sources for improved estimates of population size and survival rates. Marine Mammal Science, 20, 401-423.

Jiao, Y., Reid, K. \& Smith, E. (2009) Model selection uncertainty and Bayesian model averaging in fisheries recruitment modeling. The Future of Fisheries Science in North America, Fish and Fisheries Series (eds R.J. Beamish \& B.J. Rothschild), pp. 505-524. Springer, Berlin.

Kéry, M. \& Royle, J.A. (2010) Hierarchical modelling and estimation of abundance and population trends in metapopulation designs. Journal of Animal Ecology, 79, 453-461.

Kéry, M. \& Schmidt, B.R. (2008) Imperfect detection and its consequences for monitoring in conservation. Community Ecology, 9, 207-216.

Kéry, M., Dorazio, R.M., Soldaat, L., van Strien, A., Zuiderwijk, A. \& Royle, J.A. (2009) Trend estimation in populations with imperfect detection. Journal of Applied Ecology, 46, 1163-1172.

Kinzey, D., Olson, P. \& Gerrodette, T. (2000) Marine mammal data collection procedures on research ship line-transect surveys by the Southwest Fisheries Science Center. NOAA, SWFSC Administrative Report LJ-0008 .

Krebs, C.J. (2001) Ecology: The Experimental Analysis of Distribution and Abundance, 5th edn. Benjamin Cummings, Menlo Park.

Link, W.A. \& Barker, R.J. (2010) Bayesian Inference with Ecological Applications. Academic, London.

Lunn, D.J., Thomas, A., Best, N. \& Spiegelhalter, D. (2000) WinBUGS - a Bayesian modelling framework: concepts, structure, and extensibility. Statistics and Computing, 10, 325-337.

Marques, F.F.C. \& Buckland, S.T. (2004) Covariate models for the detection function. Advanced Distance Sampling (eds S.T. Buckland, D.R. Anderson, K.P. Burnham, J.L. Laake, D.L. Borchers \& L. Thomas), pp. 31-47. Oxford University, New York.

Mizroch, S.A., Rice, D.W., Zwiefelhofer, D., Waite, J. \& Perryman, W.L. (2009) Distribution and movements of fin whales in the North Pacific Ocean. Mammal Review, 39, 193-227.
Morris, W.F. \& Doak, D.F. (2002) Quantitative Conservation Biology. Sinauer, Sunderland.

NMFS, National Marine Fisheries Service. (2005) Revisions to guidelines for assessing marine mammals stocks. Available at: http://www.nmfs.noaa.gov/ $\mathrm{pr} / \mathrm{pdf} / \mathrm{sars} /$ gamms2005.pdf.

NMFS, National Marine Fisheries Service (2006) Draft Recovery Plan for the Fin Whale (Balaenoptera physalus). National Marine Fisheries Service, Silver Spring, MD.

Rodrigues, A.S.L., Pilgrim, J.D., Lamoreux, J.F., Hoffmann, M. \& Brooks, T.M. (2006) The value of the IUCN Red List for conservation. Trends in Ecology and Evolution, 21, 71-76.

Royle, J.A. \& Dorazio, R.M. (2008) Hierarchical Modeling and Inference in Ecology. Academic, London.

Spiegelhalter, D.J., Best, N.G., Carlin, B.P. \& van der Linde, A. (2002) Bayesian measures of model complexity and fit. Journal of the Royal Statistical Society B, 64, 583-639.

Spiegelhalter, D.J., Thomas, A., Best, N. \& Lunn, D. (2007) WinBUGS User Manual, Version 1.4.3. Available at: http://www.mrc-bsu.cam.ac.uk/bugs [accessed on 6 August 2007].

Taylor, B.L., Martinez, M., Gerrodette, T., Barlow, J. \& Hrovat, Y.N. (2007) Lessons from monitoring trends in abundance of marine mammals. Marine Mammal Science, 23, 157-175.

Thomas, L., Burnham, K.P. \& Buckland, S.T. (2004) Temporal inferences from distance sampling. Advanced Distance Sampling (eds S.T. Buckland, D.R Anderson, K.P. Burnham, J.L. Laake, D.L. Borchers \& L. Thomas), pp. 71 107. Oxford University, New York.

de Valpine, P. \& Hastings, A. (2002) Fitting population models with process noise and observation error. Ecological Monographs, 72, 57-76.

Wade, P.R. (1998) Calculating limits to the allowable human-caused mortality of cetaceans and pinnipeds. Marine Mammal Science, 14, 1-37.

Wilberg, M.J. \& Bence, J.R. (2008) Performance of deviance information criterion model selection in statistical catch-at-age analysis. Fisheries Research 93, 212-221.

Williams, B.K., Nichols, J.D. \& Conroy, J.J. (2002) Analysis and Management of Animal Populations. Academic Press, San Diego.

Zerbini, A.N., Waite, J.M., Laake, J.L. \& Wade, P.R. (2006) Abundance, trends and distribution of baleen whales off western Alaska and the central Aleutian Islands. Deep-Sea Research, 53, 1772-1790.

Received 20 December 2010; accepted 15 May 2011

Handling Editor: Jason Matthiopoulos

\section{Supporting Information}

Additional Supporting Information may be found in the online version of this article.

Appendix S1. General likelihood expressions.

\section{Appendix S2. WinBUGS code.}

Appendix S3. Model-averaged posterior distribution summaries for density and detectability parameters from the full joint model.

Appendix S4. Posterior distribution summaries (a: tabular, b: graphical) for all parameters in the individual joint models.

Appendix S5. Posterior distribution summaries of fin whale abundance.

As a service to our authors and readers, this journal provides supporting information supplied by the authors. Such materials may be re-organized for online delivery, but are not copy-edited or typeset. Technical support issues arising from supporting information (other than missing files) should be addressed to the authors. 